\title{
Studies on Infrasound Noise Generated by Operation of Low-Power Wind Turbine
}

\author{
R. Pierzga*, T. Boczar, D. Wotzka And D. ZmarzŁy \\ Faculty of Electrical Engineering, Automatic Control and Computer Science, Opole University of Technology \\ Prószkowska 76, 45-758 Opole, Poland
}

\begin{abstract}
Subject matter of this paper deals with issues of the environmental impact of infrasound noise associated with operation of low-power wind turbines. It is now the current and relevant problem for both the cognitive and utilitarian standpoint. There is now a considerable growth in the number of such installations in Poland, Europe and in the world, due to the possibility of locating them on existing building roofs in heavily urbanized areas, and without having to build additional supporting structures. As part of the study, measurements of low frequency acoustic signals generated during operation of micro turbine equipped with a rotor of vertical axis of rotation relative to the wind direction have been performed. Analyses were carried out in order to determine the impact of wind speed and selected meteorological parameters on the level of infrasound signals emitted by the test turbine. In addition, frequency analysis of the recorded signals was performed. Then, the obtained results were subjected to comparative analysis. In summary, the achieved results were referred to the limits of sound pressure intensity level of infrasound signals as specified for the working environment in accordance with the Polish Standard PN-Z-01338.
\end{abstract}

DOI: 10.12693 /APhysPolA.124.542

PACS: 43.28.Dm, 43.50.Ed, 43.50.Cb, 43.50.Rq, 43.50.Yw, 88.50.jj, 88.50.gp

\section{Introduction}

The work of wind turbines generates noise, including infrasonic noise, which is defined as the acoustic emission at the frequency range from $1 \mathrm{~Hz}$ to $20 \mathrm{~Hz}$ [1]. The problem of infrasound being generated applies also to small wind turbines; generation of noise and vibration is a general problem during operation of electric power devices. In case of such installations, it may be even greater, because installations of small wind turbines are possible on buildings, houses and public premises, so in the immediate vicinity of work and live places. Furthermore, applicable standards on noise produced by wind turbines refer to large industrial installations, and standards defining the effect of infrasonic noise are specified only for workplaces, at eight-hour work cycle, which in the case of a small wind turbine or a group of such turbines are installed on residential building, it may be insufficient to assess the effect of the generated infrasound noise [2]. Meanwhile, excessive exposure to infrasound noise can lead to problems of concentration, lower productivity, hyperactivity, feeling as if internal organs are "vibrating", sleep difficulties, or even vibroacoustic disease in some cases defined as a set of many ailments caused by long-term exposure to low-frequency noise [3-11].

The previously mentioned standards referring to large wind turbines define methodology for measuring noise level generated by work of a wind turbine and simultaneously allow the possibility to extend these measurements to include infrasound signals, by not defining for this

\footnotetext{
*corresponding author; e-mail: radekpierzga@o2.pl
}

purpose a separate methodology. The work involved performing infrasound noise measurement of a small vertical-axis wind turbine (VAWT) and sound pressure level (SPL) was determined, which allowed the assessment of the effect in the measurement point. The obtained results of sound pressure measurements were also analysed according to the DIN ISO 7196:2002 standard [1], using $G$ weighting curve. The results were compared to those obtained from other small wind turbine, in order to identify differences in sound levels generated at the range of infrasound noise. Basic meteorological parameters were also subject of the measurements, in accordance with the standard [2].

\section{Test subject}

The test turbine was Savonius drag-type wind turbine with a rated power of $1 \mathrm{~kW}$. The turbine is part of the research installation consisting of 5 wind turbines of low power and installed on the building of the Institute of Electrical Power Engineering and Renewable Energy of the Opole University of Technology.

Sound pressure measurements of infrasound signals for both wind turbines were taken using the same measuring set from Brüel \&Kjær, consisting of a microphone, type 4190 , which allow recording changes in sound pressure level in the range from $1.2 \mathrm{~Hz}$ to $20 \mathrm{kHz}$. The microphone was connected to instrument, type LAN-XI 3050 Version A-60, which allows performing specialized sound pressure level measurements. The recorded measurement data were stored and analysed using specialized software integrated with the PulseLabShop v. 15.1 measuring set. The measured frequencies were in the range from $1.2 \mathrm{~Hz}$ to $20 \mathrm{kHz}$, for which the response is linear within $\pm 3 \mathrm{~dB}$. Prior and post measurements, calibration 
of the microphone was conducted using acoustic calibrator KA-50. I class calibrator was designed for acoustic mapping of measuring path of sound level meters and equipped with measurement microphones with: $1^{\prime \prime}, 1 / 2^{\prime \prime}$ and $1 / 4^{\prime \prime}$ in diameter [9]. Meteorological parameters were also recorded, such as: wind speed and direction, temperature, pressure and humidity. The measurements were performed using the weather station Ventage Pro 2, type 6152EU (Table I).

TABLE I

Summary of measured wind speeds occurring during measurements of infrasound signals generated by turbine being tested.

\begin{tabular}{c|c|c|c|c}
\hline \hline & Max & Min & Mean & $\begin{array}{c}\text { Standard } \\
\text { deviation [\%] }\end{array}$ \\
\hline wind speed [m/s] & 6 & 1.3 & 3.8 & 21.3 \\
wind gust [m/s] & 10.7 & 2.2 & 6.2 & 23.4 \\
temperature [ $\left.{ }^{\circ} \mathrm{C}\right]$ & 2.8 & 1.8 & 2.4 & 9.9 \\
humidity [\%] & 58 & 40 & 49 & 12.8 \\
dewpoint [ $\left.{ }^{\circ} \mathrm{C}\right]$ & -4.9 & -9.7 & -7.3 & 22.9 \\
rainfall & 0 & 0 & 0 & -
\end{tabular}

\section{Analysis and comparison of the results}

To determine the infrasonic noise effect level generated by turbines, wave forms of frequency spectra for different wind speeds were computed and it was expressed in decibels relative to threshold of audibility, which is $p_{0}=20 \mu \mathrm{Pa}$. Sound pressure level of infrasonic noise for a given wind speed was determined as arithmetic mean from all recorded sound pressure levels for the speed. Thus obtained results are presented in two graphs (Figs. 1 and 3 ). Frequency spectra of wind turbine to which data were compared are shown in Figs. 2 and 4. Figures 1 and 2 illustrate uncorrected sound pressure level wave forms of the wind turbines being compared; while in Figs. 3 and 4 there are wave forms corrected with $G$-frequency characteristic according to the standard [1], which allowed conducting comparative analysis of the derived correlations with regard to workplace and intercom pairing all these correlations.

By analysing frequency spectra presented in the above graphs, it can be stated that for both wind turbines, the maximum sound pressure level is about $95 \mathrm{~dB}$, registered for the $1 \mathrm{~Hz}$ frequency. These levels are comparable to all registered wind speeds. There is also lack of local extremes, which point to resonance frequencies. The shape of both characteristics has exponential wave form and it is independent of wind speed. The largest decrease in sound pressure level was recorded in the frequency range from 1 to $20 \mathrm{~Hz}$, and it was about $35 \mathrm{~dB}$. In later part of the wave forms, the decrease is not so dynamic and equal to about $20 \mathrm{~dB}$. Sound pressure level decreases have similar values for both described wind turbines. For both wind turbines, the recorded sound pressure levels are lower than those adopted thresholds of audibility, and

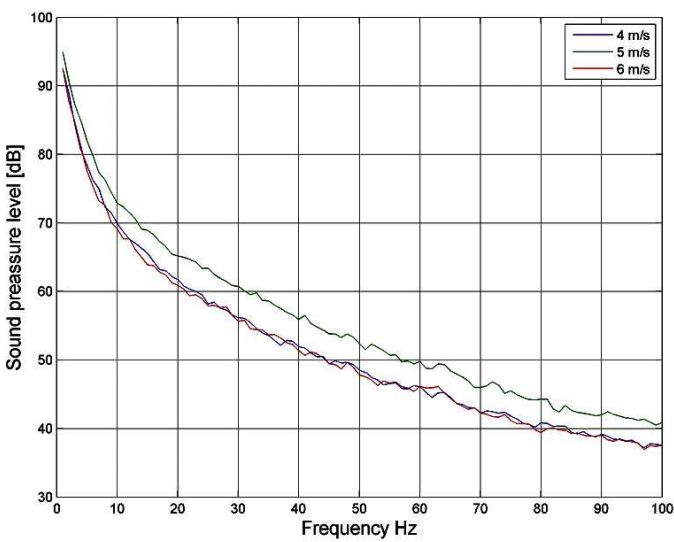

Fig. 1. Amplitude spectra of low-frequency acoustic signals without correction generated by test wind turbine, determined for wind speeds of: $3,4,5$, and $6 \mathrm{~m} / \mathrm{s}$.

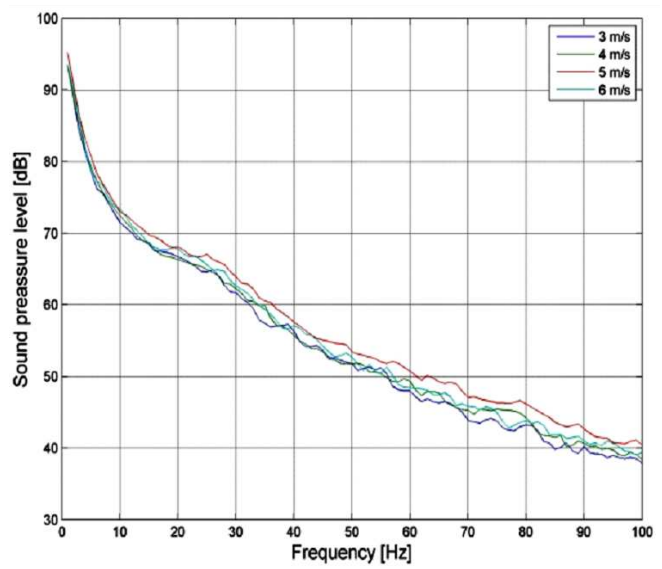

Fig. 2. Amplitude spectra of low-frequency acoustic signals corrected with G-frequency characteristic generated by wind turbine used for comparison, determined for wind speeds of: $3,4,5$, and $6 \mathrm{~m} / \mathrm{s}$.

they are: for frequencies of $4 \mathrm{~Hz}$ and $8 \mathrm{~Hz}$ - about $30 \mathrm{~dB}$ and $25 \mathrm{~dB}$, respectively, and for frequencies of $16 \mathrm{~Hz}$ and $20 \mathrm{~Hz}$ are lower, that is $12 \mathrm{~dB}$ and $6 \mathrm{~dB}$, respectively. For both turbines, the maximum sound pressure level was recorded for $5 \mathrm{~m} / \mathrm{s}$ wind speed. For the test wind turbine, it was higher by approximately $4 \mathrm{~dB}$, while for the compared wind turbine by about $2-3 \mathrm{~dB}$.

Later in the research study, the frequency spectra of sound pressure levels corrected with $G$ frequency characteristic, performed according to the standard [1] were analysed. These wave forms are presented in Figs. 3 and 4 .

Based on the wave form analysis shown in these two graphs, it can be concluded that the sound pressure level in the frequency range from 1 to $10 \mathrm{~Hz}$ is much lower than in the case, when frequency correction is not applied yet. In the range from 1 to $20 \mathrm{~Hz}$ for both cases, an increase in sound pressure level is followed, which reaches the range of approximately $71-76 \mathrm{~dB}$ for $20 \mathrm{~Hz}$ frequency, repre- 


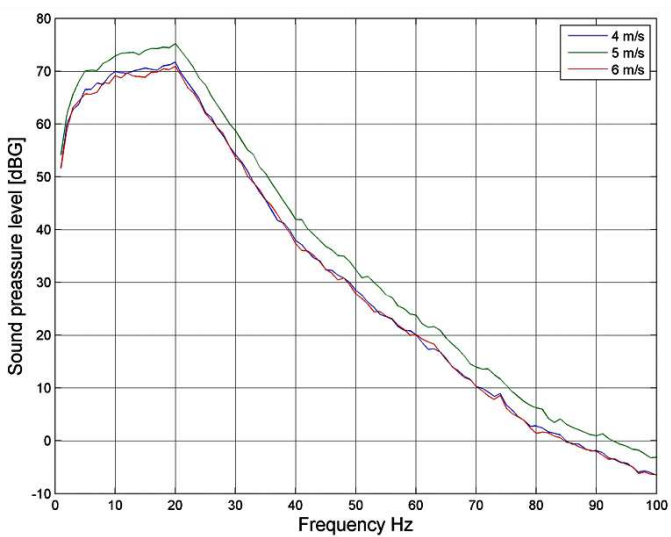

Fig. 3. Amplitude spectra of low-frequency acoustic signals corrected with $G$-frequency characteristic generated by test wind turbine, determined for wind speeds of: 4,5 , and $6 \mathrm{~m} / \mathrm{s}$.

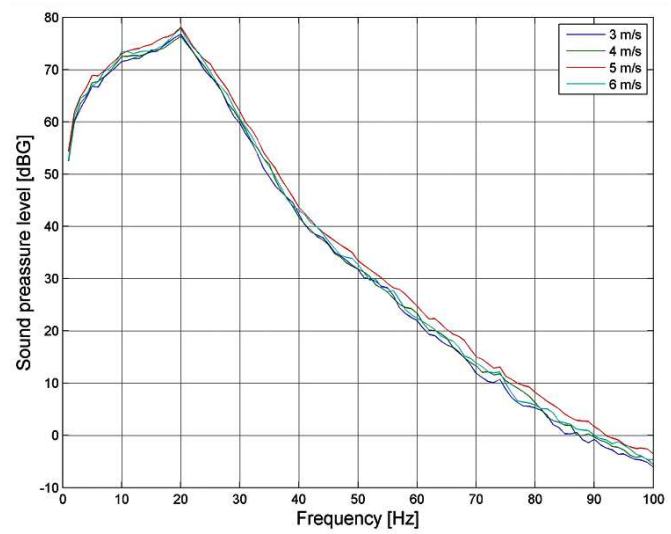

Fig. 4. Amplitude spectra of low-frequency acoustic signals corrected with $G$-frequency characteristic generated by wind turbine used for comparison, determined for wind speeds of: $3,4,5$, and $6 \mathrm{~m} / \mathrm{s}$.

senting the maximum value for the corrected wave form. In the frequency range from $20 \mathrm{~Hz}$ to $100 \mathrm{~Hz}$, the sound pressure level decreases by about $80 \mathrm{~dB}$. After applying frequency correction, the effect of infrasonic noise in the band from 10 to $25 \mathrm{~Hz}$ "increased". For $20 \mathrm{~Hz}$, the sound pressure level reached $76 \mathrm{~dB}$ after correction, which is close to threshold of hearing for this frequency.

Two-dimensional spectrograms as time-frequency representation, computed using short-term Fourier transformations (STFT) were also analysed. They represented time-frequency images of infrasonic noise generated by both wind turbines under comparable wind conditions (Figs. 5 and 6).

Analysing these spectrograms can be found that in both wind turbines, repeated and frequent fluctuations in sound pressure level occur. The fluctuations relate to the frequency range up to about $30-40 \mathrm{~Hz}$. The highest SPL values occur in low-frequencies and in the band

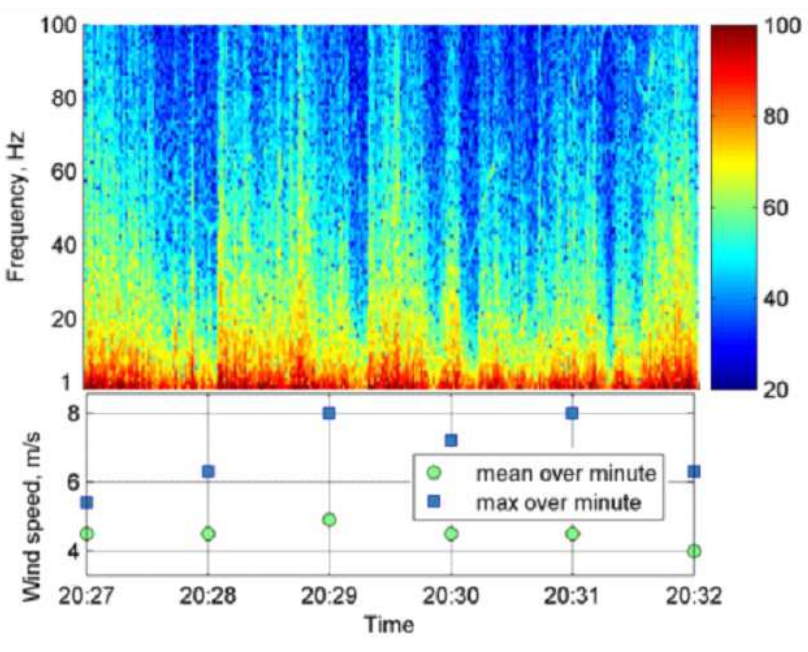

Fig. 5. Spectrogram of low-frequency acoustic signals generated by test wind turbine.

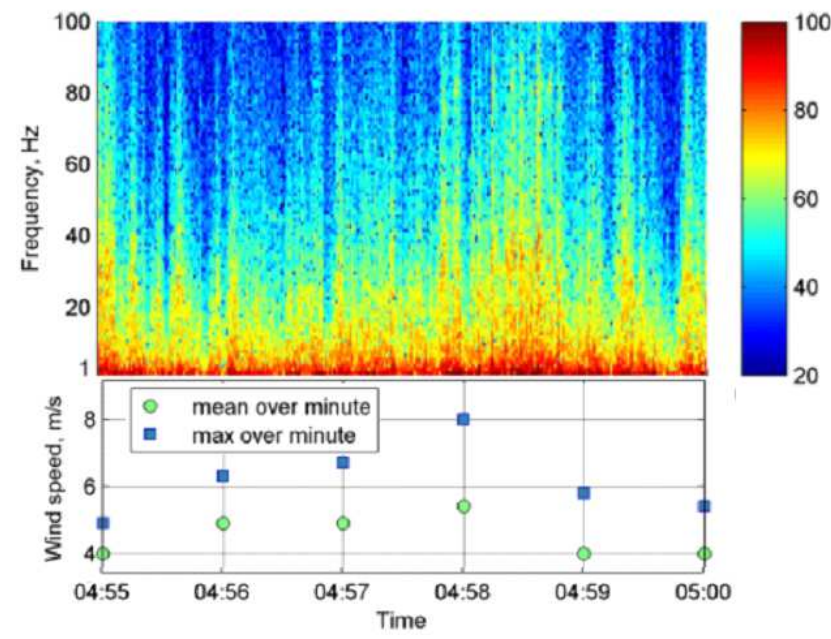

Fig. 6. Spectrogram of low-frequency acoustic signals generated by wind turbine used for comparison.

above $15 \mathrm{~Hz}$, then significant decrease in sound pressure level can be seen.

In the final stage, comparison is presented between the obtained sound pressure level values with the $G$-frequency characteristic and limit values defined in relevant standards for workplaces. For the test wind turbine, these values were presented in Table II. All values refer to eight-hour working day defined in standards. For comparison purposes, eight-hour exposition time to infrasonic noise generated by the work of described wind turbines and sound pressure level equal to the arithmetical average calculated from all conducted measurements were adopted. With this assumption it is possible to compare the effects of infrasonic noise emitted from both turbines during their work for the eight-hour working day. 
TABLE II

Comparative tabulation of equivalent sound pressure level values referred to 8-hour working day or a working week (8$\mathrm{h}$ ESP) derived from measurements and current regulations for wind turbine being tested.

\begin{tabular}{l|l|l|l}
\hline \hline $\begin{array}{l}\text { One-third octave } \\
\text { band center fre- } \\
\text { quency [Hz] }\end{array}$ & $\begin{array}{l}\text { 8-h ESP deter- } \\
\text { mined from mea- } \\
\text { surements [dB] }\end{array}$ & $\begin{array}{l}\text { 8-h ESP } \\
\text { based } \\
\text { on [5] [dB] }\end{array}$ & $\begin{array}{l}\text { Max. sound } \\
\text { pressure } \\
\text { level [dB] }\end{array}$ \\
\hline $10 ; 12.5 ; 16$ & $70.6 ; 70.9 ; 71.5$ & 80 & 100 \\
20 & 72.6 & 90 & 110 \\
25 & 63.8 & 105 & 125 \\
$31.5 ; 40$ & $54.1 ; 39.0$ & 110 & 130
\end{tabular}

\section{Summary}

Based on the research studies, analysis and comparisons, the following conclusions can be stated:

- For both wind turbines being analysed, the maximum sound pressure level for infrasound noise was measured at the frequencies from 1 to $20 \mathrm{~Hz}$, and it was below the threshold of hearing.

- For both wind turbines, the maximum infrasonic sound pressure level, when $G$ weighing curve is applied, was captured at the frequency of $20 \mathrm{~Hz}$, and ranged from 71 to $76 \mathrm{~dB}$, depending on the wind speed.

- In the case of both wind turbines, the measured values were much lower than the threshold values stated in relevant standards. It should be noted, however, that these values refer to the eight-hour working day for a work station. For both wind turbines, wind speed changes had little effect on fluctuations in sound pressure level; in both cases, the maximum sound pressure level was recorded for wind speed of $5 \mathrm{~m} / \mathrm{s}$.
It should be noted that exposure time per day to infrasound noise generated by small wind turbines can be significantly greater than limits expressed in standards and regulations for workplaces at eight-hour working day. It is therefore necessary to continue research works aimed at determination of the potential impact of this type of installation in the widest possible extent.

\section{References}

[1] PN-ISO 7196:2002, Acoustics - Frequency weighting characteristic for infrasound measurements.

[2] PN-Z-01338:2010, Acoustics - Measurement and evaluation of infrasound noise at work.

[3] K. Barczak, Bull. Pol. Acad. Sci., Techn. Sci. 59, 409 (2011).

[4] M. Björkman, J. Sound Vibrat. 277, 567 (2004).

[5] S. Borucki, T. Boczar, A. Cichon, Arch. Acoust. 36, 823 (2011).

[6] M. Alves-Pereira, N.A.A. Castelo Branco, Prog. Biophys. Mol. Biol. 93, 256 (2007).

[7] D. Wotzka, T. Boczar, D. Zmarzly, Acta Phys. Pol. A 116, 428 (2009).

[8] C.S. Pedersen, H. Møller, K.P. Waye, J. Low Freq. Noise Vibrat. Active Control 27, 131 (2008).

[9] D. Wotzka, D. Zmarzly, T. Boczar, Acta Phys. Pol. A 118, 1272 (2010).

[10] K. Gut, S. Drewniak, Acta Phys. Pol. A 120, 630 (2011).

[11] K. Persson Waye, E. Ohrstrom, J. Sound Vibrat. 250, 65 (2002). 